\title{
Taxation and Pollution Control: An Illustration \#
}

\author{
A. H. Barnett*
}

In recent years economists have devoted a great deal of attention to the issue of taxation for environmental quality control. Numerous writers have observed that it is conceptually possible to achieve optimal pollution control by imposing a per unit emissions tax equal to the value of marginal abatement costs at an optimal emissions level. However, optimal taxation requires a great deal of information, both on the technology of abatement and on the social cost caused by the emission of harmful substances. For this reason, Kneese and Bower (1968), Baumol (1972) and others have proposed adoption of a goal more modest than genuine optimality based on marginal social benefits in relation to costs. They suggest that taxes be set to achieve some administratively determined quality objectives instead. Taxation to achieve administratively determined quality standards requires information only on abatement costs and technical information relating emissions from each polluter to observed environmental quality levels. ${ }^{1}$ This does not mean that these information requirements are trivial. Indeed the lack of reliable and comprehensive information on abatement cost functions is a major difficulty in developing efficient environmental control strategies. However, adequate information for roughly computing taxes which can achieve specified quality objectives is available for some important environmental problems. This paper addresses one such problem.

The purpose of this paper is to present a framework which can be applied to calculate taxes to satisfy preset environmental quality standards and to illustrate the operation of that framework by calculating emission taxes for selected sulfur oxide emitters in Allegheny County, Pennsylvania. The framework is also used to show that policies requiring uniform control standards for all polluters can result in substantial increases in control costs over policies which recognize differential abatement costs across firms.

The conceptual model is presented in Section I. This model consists of (i) a modified form of a mathematical program formulated by Gorr, Gustafson and Kortanek (1972) which can be solved for a set of polluter-

\footnotetext{
\#The author is grateful to Roger Sherman, Edgar O. Olsen, James Bradley, Lark E. Adams and two referees for helpful comments on earlier drafts of this paper.

* Department of Economics, Auburn University, Alabama 36849.
} 
specific emission requirements and (ii) a procedure for calculating emission taxes to induce polluters to emit only their alloted quota of pollutants. To illustrate the operation of this model we study five polluters, two electric utilities and three steel plants. All five plants are coal fired and have similar emission control problems. These polluters account for approximately 75 percent of the ground level concentration of sulfur oxides in the Clairton sub-basin of Allegheny County. For purposes of this illustration, air quality is measured at three ground level points which are among those chosen by Carbone and Sweigart (1976) as locations most likely to experience maximum area sulfur oxide concentrations.

The calculation of sulfur taxes for the five polluters is accomplished in three steps. The first step involves estimating pollution abatement cost functions, which is undertaken in Section II. In the second step these cost functions are incorporated into the programming model (developed in Section I) and the program is solved for optimal levels of emission for each polluter. Section III is devoted to this task. The final stage is undertaken in Section IV, where the estimated cost functions from step one and the solution set of emissions from step two are used to calculate a set of sulfur emission taxes which will induce the five polluters into emitting amounts of sulfur oxides which are consistent with the specified quality objectives. Conclusions are presented in Section V.

\section{The. Model}

Let $\mathrm{A}$ denote an air quality region and $\mathrm{z}_{\mathrm{i}} \in \mathrm{A}$ denote a point in $\mathrm{A}$. Let the ıumber of controlled sources of the air pollutant be $\mathrm{N}$ and the amount of the pollutant emitted by the jth source be represented by $q_{j}, j=1, \ldots, N$. Air quality is assumed to be measured at ground level and the observed concentration of the pollutant at any $z_{i}$, denoted by $S_{i}$. is represented by

$$
S_{i}=u_{o}\left(z_{i}\right)+\sum_{j=1}^{N} q_{j} u_{j}\left(z_{i}\right)
$$

where

$$
\begin{aligned}
\mathrm{u}_{\mathrm{j}}\left(\mathrm{z}_{\mathrm{i}}\right)= & \text { an atmosphere-diffusion-index }{ }^{2} \text { representing the } \\
& \text { micrograms/cubic meter of the pollutant observed } \\
& \text { at } \mathrm{z}_{\mathrm{i}} \text { which can be attributed to polluter } \mathrm{j} \text { for a } \\
& 1 \text { ton/day emission rate, }
\end{aligned}
$$

$\mathrm{u}_{0}\left(\mathrm{z}_{\mathrm{i}}\right)=$ the amount of the pollutant observed at $\mathrm{z}_{\mathrm{i}}$ which is attributable to background or uncontrollable area sources. 
Compliance with air quality control standard requires

$$
\hat{S}_{\mathrm{i}} \geqslant \mathrm{u}_{0}\left(\mathrm{z}_{\mathrm{i}}\right)+\sum_{j=1}^{\mathrm{N}} \mathrm{q}_{\mathrm{j}} \mathrm{u}_{\mathrm{j}}\left(\mathrm{z}_{\mathrm{i}}\right),
$$

where $S_{i}$ is the maximum ground level concentration of the pollutant allowed at $z_{i}$ by the air quality standard.

Given a set of administratively determined ambient standards at $\mathrm{M}$ sites, $\hat{\mathrm{S}}_{1}, \ldots, \hat{\mathrm{S}}_{\mathrm{M}}$, optimal emission allotments for polluters are those which satisfy the standards while minimizing the summed abatement costs of all polluters. These optimal allotments are determined by solving the following mathematical program:

\section{Program I}

Minimize $\quad \sum_{j=1}^{N} c_{j}\left(\hat{q}_{j}-q_{j}\right)=\sum_{j=1}^{N} c_{j}\left(\Delta_{j}\right)$

Subject to

$$
u_{0}\left(z_{i}\right)+\sum_{j=1}^{N} q_{j} u_{j}\left(z_{i}\right) \leqslant \hat{S}_{i} \text { for each } z_{i} \epsilon A
$$

where

$\hat{\mathrm{q}}_{\mathrm{j}}=$ the amount of the air pollutant emitted by point source $\mathrm{j}$ when no sanctions or controls are imposed on polluters,

$q_{j}=$ actual emissions by point source $\mathbf{j}$,

$\Delta_{\mathrm{j}}=\hat{\mathrm{q}}_{\mathrm{j}}-\mathrm{q}_{\mathrm{j}}=$ pollution abatement by the $\mathrm{jth}$ emitter,

$C_{j}\left(\Delta_{j}\right)=$ the cost of abatement for point source $j$.

Let $\Delta_{\mathrm{j}}^{*}$, for each $\mathrm{j}=1, \ldots, N$, represent elements in the solution set for Program I. Assuming that all individual marginal abatement cost functions are monotonically increasing in the amount of the abatement, optimal taxes are found by evaluating each $\frac{\mathrm{dc}_{\mathrm{j}}\left(\Delta_{\mathrm{j}}\right)}{d \Delta_{\mathrm{j}}}$ at each corresponding $\Delta_{\mathrm{j}}^{*}$. A polluter will discharge, and pay the tax for, all units of pollution for which the per unit tax is less than the marginal cost of abatement and will withhold all units of pollution for which the tax exceeds his incremental abatement costs. Thus, setting an emmission tax for each polluter equal to that polluter's marginal abatement cost at his optimal level of discharge, $\Delta_{\mathrm{j}}^{*}$, will simultaneously minimize joint abatement cost, $\sum_{j}^{N} c_{j}\left(\Delta_{j}\right)$, and satisfy the set of air quality objectives. 


\section{The Cost of Abatement}

Coal combustion, whether in steel or electric plants, generates two major pollutants-particulate matter and sulfur oxides. Historically, air pollution control efforts have focused on the removal of particulates because their emission causes the most obvious effects-soot and smoke. This concentration of control efforts has generated a well developed and highly effective particulate control technology. Mechanical collectors and electrostatic precipitators have been used to remove particles from stack gases for over 50 years. Precipitators which can remove 97 to 99 percent of the particles suspended in stack gases have been available for over a decade and are now used widely. This does not mean that soot and smoke have ceased to be problems in air quality control, however. The regulation of particulate emissions continues to be a major function of environmental control agencies, but in recent years air quality research has fostered an increased awareness of other hazardous materials present in effluent gases. In particular, sulfur oxide emissions have become a major source of environmental concern.

Sulfur oxides are formed from the combustion of in-fuel sulfur and atmospheric oxygen. Their emission can be controlled in three main ways: (i) by removing sulfur from fuels prior to combustion, (ii) by cleaning stack gases after combustion, or (iii) by using fuels with lower levels of naturally occurring sulfur.

Removal of sulfur from coal prior to combustion is difficult because coal contains two forms of sulfur-pyritic and organic. Pyritic sulfur can be partially removed by washing and gravity separation. However, cleaning experiments indicate that washing and gravity separation are impractical because of the inability to completely remove pyrites and because of the high proportion of organic sulfur present in coal. ${ }^{3}$ Since organic sulfur is chemically bound, full removal of sulfur can be accomplished only by transforming coal into a synthetic fuel, such as coal gas. However, despite recent advances in coal gas technology, it is still in the experimental stage and is unlikely to be commercially feasible in the near future.

Stack gas desulfurization can be accomplished by using a variety of gas scrubbing procedures, such as dry limestone injection, wet limestone injection, dolomite injection, catalytic oxidation, soluble sodium scrubbing or double alkali scrubbing. Estimates of the costs and effectiveness of scrubbers installed in existing plants vary widely but, even when the lowest estimates of costs are used, scrubbers appear very expensive. ${ }^{4}$ Additionally, scrubbers produce large amounts of sludge as a by-product of the cleaning process and the disposal of this sludge can produce troublesome environmental problems.

The most direct way to desulfurize coal is by switching to coal with lower levels of naturally occurring sulfur. Given current technology, fuel switching also appears the least costly method of controlling sulfur oxide emissions. This is especially true for plants located near low-sulfur coal deposits because of the relatively low mine to plant transportation cost. The five plants used in this study are near large low sulfur deposits located primar- 
ily in West Virginia and Kentucky. Thus we shall assume in calculating sulfur oxide abatement costs that fuel switching is the only device used for reducing emissions. ${ }^{5}$

\section{Sulfur Content and Coal Prices}

Assuming that fuel switching is to be used for reducing sulfur oxide emissions, the objective function in Program I can be written as follows:

$$
\text { Minimize } \quad \sum_{j=1}^{N} h_{j}\left(P_{j}-P_{b}\right) \text {, }
$$

where

$h_{j}=$ average daily heat demand for the jth polluter, assumed constant,

$P_{j}=$ the price paid for coal by the jth polluter, which is a function of its sulfur content,

$P_{b}=$ the price paid for coal by firms that are indifferent to the sulfur content of the fuels they burn,

so that

$P_{j}-P_{b}=$ the premium paid by the jth polluter for low sulfur coal.

Since $P_{b}$ is the same for all firms ${ }^{6}$ and the $h_{j}$ 's are assumed constant,

$\mathrm{N}$

$\sum \mathrm{h}_{\mathrm{i}} \mathrm{P}_{\mathrm{b}}$ is constant. Thus, the solution set for a program with (3) as an $j=1$

objective function is identical to that obtained with the following objective function:

Minimize $\quad \sum_{\mathrm{j}=1}^{\mathrm{N}} \mathrm{h}_{\mathbf{j}} \mathrm{P}_{\mathrm{j}}$.

Estimates of abatement costs must therefore begin with an estimate of a price equation for coal.

The Determinants of Coal Prices

The five plants for which Program I is to be computed use small amounts of coal relative to the total coal production in the Appalachian region. This is true not only for each individual plant but also for the five 
plants taken together. Because their usage is so small relative to usage from local markets, these firms are assumed to be unable to influence market prices. That is, they are assumed to behave as perfectly competitive buyers. Furthermore, since coal markets are relatively competitive on the supply side, price discrimination is unlikely. ${ }^{7}$ Thus, all buyers are assumed to pay the same price for comparable coal. Differences in actual prices paid for coal are therefore assumed to be determined by the qualitative characteristics of the coal purchased and by differences in the terms of purchase. ${ }^{8}$ The problem that must be resolved then is how coal prices vary with the chemical composition of coal, in particular with in-fuel sulfur, and with the terms of purchase.

Ash and moisture are undesirable components of coal. Ash is the incombustible residue left when coal is burned and the source of particulates in stack gases. Moisture is the loss in weight of coal when heated at a temperature of 104 to $110^{\circ} \mathrm{C}$. for one hour..$^{9}$ Since both moisture and ash are incombustible they reduce the heating value of coal per unit weight. Additionally, high moisture content may necessitate the addition of fuel oil to initiate combustion.

Volatile matter and fixed carbon are desirable components of coal. Volatile matter includes carbon-hydrogen compounds, free oxygen, nitrogen and other gas-forming components of dry coal. Fixed carbon is the combustible material remaining in coal after volatile matter is driven off. ${ }^{10}$ The relative amounts of volatile matter, fixed carbon, ash and moisture present in coal determine its heat content per unit weight. Thus, British thermal units (Btu's) per pound of coal is a composite measure of these four constitutents.

Coal users view sulfur as undesirable for several reasons. Most importantly, federal and state regulations limit sulfur oxide emissions, often by regulating the sulfur content of fuels burned. Furthermore, when mixed with atmospheric water vapor sulfur oxides produce corrosive acids which are not only environmentally detrimental but may also damage plant and equipment. ${ }^{11}$ In the coking and sinter processes required for steel and iron production, some in-fuel sulfur is retained in coke and is transmitted to the finished steel and iron. Thus, high levels of sulfur in coal make it unsuitable for metallurgical purposes.

Coal prices also vary with the timing and terms of agreements under which purchases are made. ${ }^{12}$ Between 1948 and 1969 the price of coal used by steam electric plants was relatively stable, varying from an average annual high of $\$ 5.08$ per ton in 1957 to a low of $\$ 4.39$ in 1963 . The mean price for this period was $\$ 4.75$ per ton and the standard deviation in annual mean prices was $\$ 0.21$. But in 1970 prices increased 25 percent. Between 1971 and 1973 the increase was 36 percent and in 1974 prices rose 93.4 percent above 1973. A more modest 19 percent increase was recorded in 1975. Furthermore, these figures understate price changes for newly contracted coal and spot purchases because they include sales made under contractual agreements negotiated in previous years. ${ }^{13} \mathrm{~A}$ variety of factors have generated these price increases and have producèd 
general uncertainty among buyers about the short-term availability of adequate quantities of coal. The 1973-74 OPEC oil embargo and subsequent increases in oil prices, the introduction of new mine safety regulations and anticipation of a UMW strike in the second half of 1974 have been major factors contributing to the instability of coal markets since 1969.

The problem of estimating a coal price equation from information on current coal deliveries is thus complicated because actual prices for contract purchases differ depending upon the period in which the agreement was made, and spot prices differ from contract prices both because of the greater response of spot prices to current market conditions and because firms have in recent years been willing to pay a premium for the reduced uncertainty afforded by contractual agreements.

\section{The Data}

Since July 1972 the Federal Power Commission (FPC) has required all electric utilities to file monthly reports detailing the cost and qualitative characteristics of each fuel delivery received at each plant during the month. Among the characteristics reported are delivered price per million Btu, Btu's per pound of coal, percent ash and percent sulfur. Utilities are also required to report whether deliveries were purchased spot or under contract, though specification of dates on which contracts were initiated and the length of the contractual period are not required.

Comparable data are not available for steel producers. But almost all coal produced in the Eastern U.S. has coking properties ${ }^{14}$ and coking coal, except that with high levels of sulfur or ash, is generally suitable for metallurgical purposes. ${ }^{15}$ Since most low-sulfur, low-ash coal used by eastern utilities is also suitable for steel production, low-sulfur premiums should be the same for both industries. Thus, these premiums can be estimated for both industries using available data from electric utilities only.

Low sulfur premiums are estimated here using 1976 FPC fuel price and quality data for the coal-fired electric utilities in and around the Pittsburgh metropolitan area. 1976 data are used because this is the only year since the introduction of monthly fuel price and quality reports that a major structural change has not occurred in coal markets. ${ }^{16}$ Further, since only two of the five plants to be used in computing Program I are electric utilities, data from the seven other coal-fired electric utilities in the Pittsburgh area are used to provide additional observations. The choice of additional plants from which observations are taken was limited to those polluters relatively near the five plants used in Program I because the FPC reports include only delivered prices, and transportation costs constitute a significant part of delivered coal prices. Since coal buyers in the same general area bear approximately equal transportation costs for coal of any specific quality, limiting the selection of plants to those in the immediate Pittsburgh area should reduce the problem of accounting for differences in the cost of transporting coal. 
An Estimated Coal Price Equation

The data described above are used here to estimate the following covariance model: ${ }^{17}$

$$
\mathrm{P}_{\mathrm{jit}}=\alpha+\beta_{1} \mathrm{~S}_{\mathrm{jit}}^{-1}+\beta_{2} \mathrm{Btu}_{\mathrm{jit}}+\beta_{3} \mathrm{C}_{\mathrm{jit}}+\sum_{\mathrm{i}=1}^{8} \gamma_{\mathrm{i}} \mathrm{E}_{\mathrm{jit}}+\sum_{\mathrm{t}=1}^{11} \tau_{\mathrm{t}} \mathrm{M}_{\mathrm{jit}}+\epsilon_{\mathrm{jit}},
$$

where

$\mathrm{P}_{\mathrm{jit}}=$ the price, in cents per $10^{6} \mathrm{Btu}$, of the jth shipment of coal to plant i during month $\mathrm{t}$;

$\mathrm{S}_{\mathrm{jit}}=$ the pounds of in-fuel sulfur per $10^{6}$ Btu contained in shipment jit;

$\mathrm{Btu}_{\mathrm{jit}}=$ Btu's per pound of coal for shipment jit;

$\mathrm{C}_{\mathrm{jit}}=1$ for contract purchases,

$=0$ otherwise;

$E_{j i t}=1$ for deliveries to the ith plant, $=0$ otherwise $(i=1, \ldots, 8)$;

$\mathrm{M}_{\mathrm{jit}}=1$ for deliveries during month $\mathrm{t}$, $=0$ otherwise $(\mathrm{t}=1, \ldots, 11)$.

Current sulfur emission control regulations require many plants to burn fuels with sulfur contents which do not exceed an amount specified by state and federal pollution control agencies. Admissible sulfur varies among these plants depending upon the general state requirements, the ambient air quality in the area in which each polluter is located, the age of the plant, ${ }^{18}$ the proximity of the polluter to metropolitan areas and other factors. Thus, there is a hierarchy of coal users ranging from those subject to very strict sulfur emission requirements to those who are allowed to burn any coal they like. Since additional in-fuel sulfur offers no advantages to coal users, those polluters who are not subject to emission controls will either be indifferent to the amount of sulfur present in the fuels they burn or they will view it as undesirable. Assuming that coal production is competitive and further assuming that there is neither an excess demand nor an excess supply of coal, such users will pay a price no less than the incremental cost of production, say $P_{b}$. If there were sufficient clean coal to satisfy the needs of controlled polluters at a price equal to $\mathrm{P}_{\mathrm{b}}$ then lowsulfur coal would carry no premium. ${ }^{19}$ However, casual empiricism 
suggests that such coal does carry a premium and the marginal premium appears to increase with lower levels of in-fuel sulfur. For this reason, sulfur appears in equaiton (5) in inverse form. ${ }^{20}$

The heating value of $\mathrm{coal}^{21}$ is included as a regressor in equation (5) because we hypothesized that coal buyers are willing to pay a higher price per Btu for coal containing more Btu's per pound. There are two reasons for believing that the price per Btu and the heating value of coal are positively related. First, other things equal, the heating value of coal is lower when coal contains more ash and moisture. To the extent that the Btu concentration of coal reflects its moisture and ash contents, coal users may be willing to pay a premium for higher concentrations of Btu's in coal. The second reason for believing that Btu's per pound and price per Btu might be positively related stems from the observation that coal-fired boilers may operate with increasing efficiency (i.e., produce more kilowatts per Btu) as the heating value of fuels is increased. ${ }^{22}$ That is, increasing the concentration of Btu's in coal increases the number of kilowatts produced per Btu when coal is burned.

The dummy variable $\mathrm{C}_{\mathrm{jit}}$ is included in equation (5) to adjust for differences in price for contract versus spot purchases. $E_{1 i t}, \ldots, E_{8 i t}$ are included to correct for differences in transportation costs for the different plants. $\mathrm{M}_{\mathrm{jil}}, \ldots, \mathrm{M}_{\mathrm{jill}}$ are intended to adjust for seasonal fluctuations in coal prices. Table 1 gives the results of estimating equation (5).

Setting Btu in equation (5) equal to its mean value for the sample of coal deliveries used to estimate equation (5), arbitrarily setting $\mathrm{C}_{\mathrm{jit}}$ equal to 0.75 , each $E_{j i t}$ equal to $1 / 9$ and each $M_{j i t}$ equal to $1 / 12$, the price equation can be written as follows: ${ }^{23}$

$$
\mathrm{P}_{\mathrm{j}}=77.7856+21.1093 / \mathrm{S}_{\mathrm{j}}
$$

It will be recalled that the procedure by which quality standards could be attained at minimum cost was to minimize the product of heat $u s e, h_{j}$, and the premium paid for low sulfur coal, $\mathrm{P}_{\mathrm{j}}-\mathrm{P}_{\mathrm{b}}$ as given in equation (3). The cost of removing sulfur from coal for the jth polluter is then

$$
\mathrm{C}_{\mathrm{j}}=\mathrm{h}_{\mathrm{j}}\left(\left(77.7856+21.1093 / \mathrm{S}_{\mathrm{j}}\right)-\mathrm{P}_{\mathrm{b}}\right) .
$$

The aggregate cost of removing sulfur for the five plants for which Program I is to be solved is therefore given by

$$
\mathrm{C}=\sum_{\mathrm{j}=1}^{5} h_{j}\left(\left(77.7856+21.1093 / \mathrm{S}_{\mathrm{j}}\right)-\mathrm{P}_{\mathrm{b}}\right)
$$

\section{OPTIMAL LEVELS OF DISCHARGE}

W. L. Gorr (1973) has estimated that approximately 17 micrograms per cubic meter of the observed ground-level concentration of sulfur oxides in 
the Elrama area of Allegheny County can be attributed to background and uncontrollable area sources. Thus, on this basis $\mathrm{u}_{0}\left(\mathrm{z}_{\mathrm{i}}\right)$ in Program I can be set equal to 17 micrograms/cubic meter. Gorr's estimates of the relevant atmospheric-diffusion-indices and average heat uses by polluters are given in Table 2. EPA data indicate that each pound of sulfur in coal produces approximately 1.9 pounds of sulfur oxides ${ }^{24}$ so each $q_{j} u_{j}\left(a_{i}\right)$ in Program I can be written as $1.9 \mathrm{~h}_{\mathrm{j}} \mathrm{u}_{\mathrm{j}}\left(\mathrm{z}_{\mathrm{i}}\right) \mathrm{S}_{\mathrm{j}}{ }^{25}$ Incorporating this information and the cost function estimated above into Program I yields:

TABLE 1

\begin{tabular}{|c|c|c|}
\hline $\mathrm{R}^{2}=0.28195$ & $\mathrm{n}=544$ & \\
\hline Variable & Estimated Coefficient & $\mathrm{t}$ value \\
\hline Intercept & -36.1986 & -2.21 \\
\hline $\mathrm{C}$ & 10.7157 & 4.95 \\
\hline Btu & 0.0078 & 6.42 \\
\hline $1 /$ sulfur & 21.1093 & 6.59 \\
\hline Plant 1 & 11.4291 & 2.46 \\
\hline Plant 2 & 26.1989 & 5.19 \\
\hline Plant 3 & 9.6372 & 2.06 \\
\hline Plant 4 & 2.3127 & 0.52 \\
\hline Plant 5 & 24.8582 & 5.19 \\
\hline Plant 6 & -1.3973 & -0.26 \\
\hline Plant 7 & 2.9265 & 0.70 \\
\hline Plant 8 & 8.9452 & 1.90 \\
\hline January & 7.8920 & 2.83 \\
\hline February & 6.2548 & 2.01 \\
\hline March & 2.9896 & 1.08 \\
\hline April & 1.3607 & 0.42 \\
\hline May & 1.3401 & 0.49 \\
\hline June & 3.1153 & 1.01 \\
\hline July & 2.0473 & 0.76 \\
\hline August & 0.1368 & 0.05 \\
\hline October & -0.4498 & -0.16 \\
\hline November & -4.1369 & -1.55 \\
\hline December & 0.6431 & 0.18 \\
\hline
\end{tabular}


TABLE 2

Average Daily Heat Use and Atmospheric-Diffusion-Indices

\begin{tabular}{lcccc}
\hline & & \multicolumn{3}{c}{ Atmospheric-diffusion-indices } \\
$\begin{array}{c}\text { Ground level } \\
\text { observation } \\
\text { Point }\end{array}$ & $\begin{array}{c}\text { Heat use } \\
\left(10^{9} \mathrm{Btu}\right)\end{array}$ & $\begin{array}{c}1 \\
\text { (per dav) }\end{array}$ & $\begin{array}{c}\text { (micrograms/cubic meter for a } 1 \\
\text { emission rate) }\end{array}$ \\
\hline Plant 1 & 12.98 & 1.400 & 0.084 & 0.104 \\
Plant 2 & 45.5 & 0.186 & 0.137 & 0.049 \\
Plant 3 & 52.82 & 0.280 & 0.175 & 0.065 \\
Plant 4 & 97.62 & 0.032 & 0.121 & 0.065 \\
Plant 5 & 118.22 & 0.029 & 0.072 & 0.170 \\
\hline
\end{tabular}

$\underline{\text { Program II }}$

Minimize

$$
\sum_{j=1}^{5} h_{j}\left(77.785 \dot{6}+21.1093 / S_{j}\right)
$$

Subject to

(1) $34.53 \mathrm{~S}_{1}+16.04 \mathrm{~S}_{2}+28.10 \mathrm{~S}_{3}+5.94 \mathrm{~S}_{4}+6.51 \mathrm{~S}_{5} \leqslant \hat{\mathrm{S}}_{1}-17$

(2) $2.06 \mathrm{~S}_{1}+11.84 \mathrm{~S}_{2}+17.51 \mathrm{~S}_{3}+22.44 \mathrm{~S}_{4}+16.17 \mathrm{~S}_{5} \leqslant \hat{\mathrm{S}}_{2}-17$

(3) $2.56 \mathrm{~S}_{1}+4.19 \mathrm{~S}_{2}+6.47 \mathrm{~S}_{3}+12.06 \mathrm{~S}_{4}+38.19 \mathrm{~S}_{5} \leqslant \hat{\mathrm{S}}_{3}-17$

The national air quality objective for emissions of sulfur oxides is an annual mean ground level concentration of 80 micrograms/cubic meter. Table 3 provides solutions for Program II for $\hat{S}_{i}=80$, for each $i$, and for six arbitrarily chosen alternative air quality levels. ${ }^{26}$

\section{SULFUR TAXES}

$S_{j}$ in equation (8) is measured in pounds of sulfur per $10^{6} B t u$ and $h_{j}$ is daily heat use in $10^{6} \mathrm{Btu}$ 's, so the change in total daily fuel cost as the sulfur content of coal burned by the jth polluter varies is given by

$$
\frac{\partial \mathrm{C}}{\partial \mathrm{S}_{\mathrm{j}}}=-\mathrm{h}_{\mathrm{j}}\left(\beta / \mathrm{S}_{\mathrm{j}}^{2}\right),
$$

where $\beta=21.1093$ from equation (8). Thus, assuming $h_{j}$ is constant, a daily tax on the sulfur content of coal equal to $h_{j}\left(\beta / S_{j}{ }_{j}\right)$, for $j=1, \ldots, 5$, would achieve the prescribed air quality objective. 
TABLE 3

Optimal Fuel Sulfur Content*

\begin{tabular}{cccccc}
\hline $\begin{array}{c}\text { Quality } \\
\text { Objectives** }\end{array}$ & 1 & 2 & Polluter & 4 & 5 \\
\hline 120 & 0.804 & 1.350 & 1.150 & 1.617 & 1.790 \\
100 & 0.644 & 1.086 & 0.933 & 1.299 & 1.443 \\
90 & 0.568 & 0.953 & 0.819 & 1.144 & 1.267 \\
85 & 0.531 & 0.889 & 0.761 & 1.067 & 1.181 \\
80 & 0.491 & 0.815 & 0.711 & 0.989 & 1.095 \\
75 & 0.472 & 0.756 & 0.623 & 0.933 & 1.004 \\
70 & 0.414 & 0.689 & 0.594 & 0.833 & 0.921 \\
\hline
\end{tabular}

*Optimal fuel sulfur content for each polluter is measured in pounds of in-fuel sulfur per $10^{6} \mathrm{Btu}$.

**The numbers here are total allowed ambient concentrations of sulfur oxides measured in micrograms of sulfur per cubic meter.

TABLE 4

Taxes Per Pound of In-Fuel Sulfur*

\begin{tabular}{cccccc}
\hline $\begin{array}{c}\text { Quality } \\
\text { Objectives** }\end{array}$ & 1 & 2 & \multicolumn{1}{c}{ Polluter } \\
\hline 120 & 32.66 & 11.58 & 15.96 & 8.07 & 6.58 \\
100 & 50.90 & 17.93 & 24.25 & 12.51 & 10.14 \\
90 & 65.43 & 23.10 & 31.47 & 16.13 & 13.15 \\
85 & 74.87 & 26.71 & 36.45 & 18.54 & 15.14 \\
80 & 87.56 & 31.78 & 41.76 & 21.58 & 17.61 \\
75 & 94.75 & 36.93 & 54.59 & 24.25 & 20.94 \\
70 & 123.16 & 44.47 & 59.83 & 30.42 & 24.89 \\
\hline
\end{tabular}

*Taxes are measured in 1976 cents per pound of in-fuel sulfur.

**The numbers here are total allowed ambient concentrations of sulfur oxides measured in micrograms of sulfur oxides per cubic meter. 
The optimal tax per pound of in-fuel sulfur is given by

$$
\frac{\partial \mathrm{C}}{\partial \mathrm{L}_{\mathrm{j}}}=\frac{\partial \mathrm{C}}{\partial \mathrm{S}_{\mathrm{j}}} \frac{\partial \mathrm{S}_{\mathrm{j}}}{\partial \mathrm{L}_{\mathrm{j}}}=-\beta / \mathrm{S}_{\mathrm{j}}^{2}
$$

where $L_{j}$ is pounds of in-fuel sulfur per day and $L_{j}=h_{j} \cdot S_{j}$. Hence, a tax equal to $\beta / S^{2}$ per pound of in-fuel sulfur, for each $\mathrm{j}=1, \ldots, 5$, will also achieve the prescribed air quality objective. Further, since eacn pound of sulfur in coal produces approximately 1.9 pounds of sulfur oxides, a tax equal to $\beta / 1.9 \mathrm{~S}^{2}$ per pound of sulfur oxides emitted will also be optimal. Taxes for in-fuel sulfur and for sulfur oxides are given in Table 4 and 5 .

\section{Conclusions}

Some caution should be exercised in interpreting the tax rates calculated here. The purpose of this empirical analysis has been to illustrate how optimal taxes might be calculated when predetermined quality objectives are given. The particular numerical values used for average daily heat use, air diffusion indices, coal use and coal characteristics come from Gorr (1973), EPA (1973), and Carbone and Sweigart (1976) and from reports filed by electric utilities with the FPC in 1976. Some of these values may change with time, and they are appropriate only for a particular area. In particular, average daily heat use for electric utilities will increase with growth in demand for electricity, and heat use by steel plants will vary with changing conditions in the steel industry. Coal prices have changed since 1976 and may be substantially altered by events such as strikes by workers

TABLE 5

Taxes Per Pound of Sulfur Oxides Emitted*

\begin{tabular}{cccccc}
\hline $\begin{array}{c}\text { Quality } \\
\text { Objectives** }\end{array}$ & \multicolumn{5}{c}{ Polluter } \\
\hline 120 & 17.19 & 6.09 & 8.40 & 4.25 & 3.46 \\
100 & 26.79 & 9.44 & 12.76 & 6.58 & 5.34 \\
90 & 34.44 & 12.16 & 16.56 & 8.49 & 6.92 \\
85 & 39.41 & 14.06 & 19.18 & 9.76 & 7.97 \\
80 & 46.08 & 16.73 & 21.98 & 11.36 & 9.27 \\
75 & 49.87 & 19.44 & 28.63 & 12.76 & 11.02 \\
70 & 64.82 & 23.41 & 31.49 & 16.01 & 13.10 \\
\hline
\end{tabular}

*Taxes are measured in 1976 cents per pound of sulfur oxides emitted.

**The numbers here are total allowed ambient concentrations of sulfur oxides measured in micrograms of sulfur oxides per cubic meter. 
TABLE 6

Aggregate Daily Cost Difference Between

Uniform and Cost-Minimizing In-fuel

Sulfur Requirement

\begin{tabular}{cc}
\hline Quality Objectives* & Cost Differences** \\
\hline 120 & 14,188 \\
100 & 17,606 \\
90 & 19,972 \\
85 & 21,477 \\
80 & 23,207 \\
75 & 25,141 \\
70 & 27,562
\end{tabular}

*Quality objectives are total allowed ambient concentration of sulfur oxides measured in micrograms of sulfur oxides per cubic meter.

**Cost differences are measured in 1976 dollars.

or other types of work stoppages. In short, the particular numerical values used here may only roughly approximate current conditions for the firms involved, and would have to be maintained currently to be effective.

Further, caution should be exercised in extrapolating from tax rates calculated for the five firms comprising our sample to tax rates which might be appropriate on a national or regional basis. We have assumed in calculating pollution abatement costs that the imposition of taxes on the five firms considered would not influence the structure of coal prices, and hence would not affect the cost of sulfur oxide abatement. That is, we have considered imposing taxes on these five firms assuming that controls on all other polluters are unchanged. This means that the taxes calculated are likely to underestimate the magnitude of those appropriate if implementation on a national or regional basis were considered, because wide scale implementation would certainly increase the premium paid for low-sulfur coal.

We have also ignored possible bio-chemical synergisms which may occur with multiple pollutants. For example, the health hazard caused by sulfur emissions may be increased if there are high levels of particulate emissions. Similarly, the harmful effects of a low-pH liquid pollutant may be partially neutralized when a high-pH effluent is discharged in the same vicinity. Not only are there problems of bio-chemical interdependencies in pollution control, there may also be trade-offs or process substitutions which are important for the comprehensive control of environmental quality. Polluters may improve air quality by using electrostatic precipitators to remove particulates from stack gases but the residual ash from precipitators increases the amount of solid waste produced. Stack gas scrubbers may 
remove sulfur oxides but they produce large amounts of sludge. Thus, there may be interdependencies between pollutants and abatement processes which have not been fully accounted for in the tax rates given in Tables 4 and 5 .

An additional problem deserves special note. The approach used in this study to compute abatement cost functions is relatively simple. This relative computational ease is primarily attributable to (i) the small number of polluters considered, (ii) consideration of a single pollutant and (iii) the assumption that polluters use fuel switching alone to reduce emissions. If we had considered many firms, multiple pollutants and multiple abatement strategies the practical difficulties of estimating cost functions would have been formidable.

Despite these difficulties, some useful information can be gleaned from these results. First, the relatively large dispersion in tax rates across firms suggest that polluter location, atmospheric conditions and stack and exhaust characteristics are important in formulating optimal taxes. So a uniform in-fuel sulfur requirement for all polluters will produce serious inefficiencies. Estimates of aggregate daily abatement cost differences between uniform in-fuel sulfur requirements and cost minimizing requirements are given in Table 6. Second, while recognizing the dangers in comparing tax rates calculated here to those proposed for implementation on a national basis, our calculations are in the same general range as the $20 \notin$ per pound of sulfur oxides proposed by Senator William Proxmire. This suggests that the Proxmire tax would achieve fairly stringent air quality objectives. ${ }^{27}$

\section{FOOTNOTES}

${ }^{1}$ In concept an even simpler approach could be adopted. A set of tax rates could be chosen arbitrarily and then raised if the quality achieved falls short of the preset quality standard, or lowered if too much waste abatement results. However, since emission fees required to meet a given ambient standard at minimum cost will generally be different for different emitters, in a region with many polluters it would be extremely difficult to find an efficient set of fees by trial and error. If little is known about abatement costs and dispersion coefficients the administering authority would have little way of knowing how to adjust charges to improve on the result achieved in the first iteration of the tax adjustment process.

${ }^{2}$ Air diffusion indices are generated with an atmospheric diffusion model which uses stack height, exhaust temperature, air turbulance and other factors to ascertain how waste emitted from each point source will be dispersed over the air quality control region.

${ }^{3}$ Gordon (1975), p. 140.

${ }^{4}$ Estimates of the cost of stack gas scrubbing range from $\$ 0.30$ to $\$ 0.85$ per million British thermal units, measured in 1973 dollars. Gordon (1975), p. 176.

${ }^{5}$ Ideally, we would like also to consider the possibility of a polluter varying heat use as a means of waste abatement. But since our primary purpose here is to illustrate how the procedure described above can be used to calculate taxes, and accounting for differences in heat use as taxes change would require analysis beyond the scope of this illustration, that possibility is ignored. For a discussion of sulfur oxide control strategies and their costs see Gordon (1975), pp. 128-82, or Watson (1972).

${ }^{6}$ This role of $\mathrm{P}_{\mathrm{b}}$ is discussed in more detail below.

${ }^{7}$ Evidence supporting the proposition that coal production and distribution are competitive is provided in Council on Wage and Price Control (1970).

${ }^{8}$ For example, coal delivered under contract generally sells for a different price from comparable coal purchased in spot markets.

${ }^{9}$ O'Rourke (1940), p. 866.

${ }^{10}$ O'Rourke (1940), p. 866.

${ }^{11}$ Coal combustion produces $\mathrm{SO}_{2}$ and $\mathrm{SO}_{3}$ which when mixed with water form $\mathrm{H}_{2} \mathrm{SO}_{3}$, sulfurous acid, and $\mathrm{H}_{2} \mathrm{SO}_{4}$, sulfuric acid.

${ }^{12}$ Currently, approximately 80 percent of U.S. coal sales are made under long-term contracts. Council on Wage and Price Stability (1976), p. 1.

${ }^{13}$ Council on Wage and Price Stability (1976), pp. 1-15.

${ }^{14} \mathrm{C}$ oking coal produces a hard cellular carbon residue, coke, when heated at $1500^{\circ} \mathrm{F}$ in the absence of air.

${ }^{15}$ U.S. Bureau of Mines (1975), p. 3.

${ }^{16}$ The most important changes were those brought about by the 1973-74 OPEC oil embargo and subsequent increases in the price of oil, the introduction of new mine safety regulations and a new contract between coal operators and the UMW in the second half of 1974. 
${ }^{17}$ For a discussion of the use of covaraince models in dealing with pooled cross-section and time-series observations see Kmenta (1971), pp. 516-18.

${ }^{18}$ Newer plants are often subject to more restrictive standards.

${ }^{19}$ This is not meant to imply that coal of any particular sulfur content can be mined at constant marginal cost. We mean only that there are no inherent differences in the cost of mining low-sulfur and high-sulfur coal, so any premium paid for low-sulfur coal will be due to its relative scarcity. Of course if low-sulfur coal does carry a price premium, low-sulfur deposits may be mined more intensively so the incremental cost of extraction may be higher for low-sulfur than for high-sulfur coal.

${ }^{20} \mathrm{~T}$ he nonlinear form for the sulfur variable is also a necessary concession to the mathematics of determining sulfur taxes. A fuel price equation which is linear in sulfur would imply constant marginal costs for sulfur oxide abatement and would produce a fundamental indeterminancy in calculating sulfur taxes.

${ }^{21}$ The heating value of coal is measured in BTU's per pound of coal.

${ }^{22}$ This claim was made by several of the coal buyers and electric utility engineers interviewed during the course of this study. Those persons interviewed were members of the fuel purchasing division of the South Carolina Electric and Gas Company, the engineering division of the South Carolina Public Service Commission and the Engineering Department of the University of South Carolina. Unfortunately, we were unable to find any documented evidence to support, or refute, this claim.

${ }^{23}$ We would, of course, prefer to use estimates for these variables which more closely reflect the actual conditions faced by the particular firms for which taxes are to be calculated. However, this information is not available for the steel firms in our sample. Since the primary purpose of this exercise is to illustrate how taxes might be calculated, we have adopted these arbitrary values as approximations of true values.

${ }^{24}$ See U.S. EPA (1973), pp. 1.1-1.3.

${ }^{25}$ In practice, the amount of in-fuel sulfur converted to sulfur oxides may be slightly less for steel plants than for steam electric plants. Nevertheless, since our major purpose here is illustrative we have used the EPA estimate of 1.9 pounds of sulfur oxides per pound of sulfur in coal for both steel and steam electric plants.

${ }^{26} \mathrm{~A}$ separable programming procedure is used in solving Program II. This is an approximation procedure in which the nonlinear objective function is replaced by a piecewise linear function, thus converting the problem into one which can be solved by the simplex method. A detailed description of this procedure is provided in Hadley (1964), pp. 104-47.

${ }^{27}$ The particulars of the Proxmire proposal are reported in U.S. Congressional Research Service (1973), p. 34

\section{REFERENCES}

W. J. Baumol, "On Taxation and the Control of Externalities," The American Economic Review, June 1972, 62, 307-22.

R. Carbone and J. R. Sweigart, "Equity and Selective Pollution Abatement Procedures," Management Science, December 1976, 23, 361-70.

Council on Wage and Price Stability, A Study of Coal Prices. Washington, D.C.: Government Printing Office, 1976.

Federal Power Commission, "Status of Coal Supply Contracts of New Electric Generating Units," Staff Report, January 1977.

R. L. Gordon, U.S. Coal and the Electric Power Industry. Washington, D.C.: The John Hopkins University Press, 1975.

W. L. Gorr, "Impact of the West Penn Power Company, Mitchell Station, on $\mathrm{SO}_{2}$ Air Quality in Allegheny County," presented at EPA Stationary Source Enforcement Proceeding, Washington, D.C., 1973.

W. L. Gorr, S. A. Gustafson, and K. O. Kortanek, "Optimal Control Strategies for Air Quality Standards and Regulatory Policy,"Environment and Planning, 1972, 4, 183-92.
G. Hadley, Nonlinear and Dynamic Programming. Reading, Mass.: Addison-Wesley, 1964.

J. Kmenta, Elements of Econometrics. New York, N.Y.: The Macmillan Company, 1971.

A. Kneese and B. Bower, Managing Water Quality: Economics, Technology, Institutions. Baltimore: The John Hopkins Press, 1968.

C. E. O'Rourke (ed.) General Engineering Handbook. New York, N.Y.: McGraw-Hill, 1940.

U.S. Bureau of Mines, "Bituminous Coal and Lignite: A Chapter from Mineral Facts and Problems, 1975 Edition," Washington, D.C.: Government Printing Office, 1975.

U.S. Congressional Research Service, Factors Affecting the Use of Coal in Present and Future Energy Markets. Washington, D.C.: Government Printing Office, 1973.

U.S. Environmental Protection Agency, Compilation of Air Pollutant Emission Factors, 2nd ed., Research Triangle Park, North Carolina, April 1973.

W. D. Watson, Jr., "Costs of Air Pollution Control in the Coal-Fired Electric Power Industry," Quarterly Review of Economics and Business, Autumn 1972, 12, 63-85. 